\title{
THE
}

3-7-2015

\section{Carbonate Free Electrolyte for Lithium Ion Batteries Containing Y- Butyrolactone and Methyl Butyrate}

\author{
Michael L. Lazar \\ Brett L. Lucht \\ University of Rhode Island, blucht@uri.edu
}

Follow this and additional works at: https://digitalcommons.uri.edu/chm_facpubs

Creative Commons License

\section{(c) (1) $\Theta \Theta$}

This work is licensed under a Creative Commons Attribution-Noncommercial-No Derivative Works 4.0 License.

\section{Citation/Publisher Attribution}

Lazar, M. L., \& Lucht, B. L. (2015). Carbonate Free Electrolyte for Lithium Ion Batteries Containing YButyrolactone and Methyl Butyrate. Journal of the Electrochemical Society, 162(6), A928-A934. doi: 10.1149/2.0601506jes Available at: http://dx.doi.org/10.1149/2.0601506jes accepted for inclusion in Chemistry Faculty Publications by an authorized administrator of DigitalCommons@URI. For more information, please contact digitalcommons-group@uri.edu. 


\title{
Carbonate Free Electrolyte for Lithium Ion Batteries Containing $\gamma$-Butyrolactone and Methyl Butyrate
}

\author{
Michael L. Lazar* and Brett L. Lucht**, \\ Department of Chemistry, University of Rhode Island, Kingston, Rhode Island 02881, USA
}

\begin{abstract}
A novel carbonate free electrolyte, $1 \mathrm{M}$ lithium difluoro(oxalato) borate (LiDFOB) in 1:1 gamma-butyrolactone (GBL)/methyl butyrate (MB), has been compared to a standard electrolyte, $1 \mathrm{M} \mathrm{LiPF}_{6}$ in 1:1:1 EC/DMC/DEC, and a $1 \mathrm{M}$ LiDFOB in 1:1:1 $\mathrm{EC} / \mathrm{DMC} / \mathrm{DEC}$ electrolyte. The conductivity of $1 \mathrm{M} \mathrm{LiDFOB}$ in GBL/MB is higher at low temperature, but slightly lower at higher temperature compared to the standard electrolyte. The $1 \mathrm{M} \mathrm{LiDFOB}$ in GBL/MB electrolyte has comparable cycling performance to the standard electrolyte, and better cycling performance than the $1 \mathrm{M}$ LiDFOB in EC/DMC/DEC electrolyte. The reversible cycling performance suggests that the LiDFOB in GBL/MB electrolyte forms a stable anode solid electrolyte interface (SEI) in the presence of GBL. Ex-situ surface analysis of the extracted electrodes has been conducted via a combination of XPS, FTIR-ATR and SEM which suggests that the stable anode SEI results is primarily composed of reduction products of LiDFOB.

(C) The Author(s) 2015. Published by ECS. This is an open access article distributed under the terms of the Creative Commons Attribution Non-Commercial No Derivatives 4.0 License (CC BY-NC-ND, http://creativecommons.org/licenses/by-nc-nd/4.0/), which permits non-commercial reuse, distribution, and reproduction in any medium, provided the original work is not changed in any way and is properly cited. For permission for commercial reuse, please email: oa@electrochem.org. [DOI: 10.1149/2.0601506jes] All rights reserved.
\end{abstract}

Manuscript submitted January 7, 2015; revised manuscript received February 24, 2015. Published March 7, 2015.

The widespread implementation of electric vehicles (EVs) requires further improvements in lithium ion batteries. ${ }^{1-3}$ Some of the biggest challenges for lithium ion batteries in EVs are cost, low temperature performance and battery lifetime. ${ }^{2,3}$ Improvements in the electrolyte can assist in the resolution of each of these problems. ${ }^{1,4,5}$ Most commercial electrolytes are composed of $\mathrm{LiPF}_{6}$ in a mixture of carbonate solvents. ${ }^{5}$ However, the high cost and poor thermal and hydrolytic stability of $\mathrm{LiPF}_{6}$ is problematic for the electrolyte. ${ }^{6-8}$ In addition, ethylene carbonate (EC) is typically a required component of the electrolyte due to the role of $\mathrm{EC}$ in the formation of the solid electrolyte interphase (SEI) on the anode. ${ }^{5,9-14}$ Since EC is a solid at room temperature, electrolytes containing EC frequently have poor performance at low temperature. ${ }^{15}$ Despite the shortcomings of $\mathrm{LiPF}_{6} / \mathrm{EC}$ based electrolytes, these formulations have proven very difficult to replace. While there have been significant efforts to develop novel electrolytes with superior performance to $\mathrm{LiPF}_{6}$ in carbonates, there has been limited success. The development of novel solvent systems has been more limited and frequently targeted toward specific problems such as high voltage cathodes, salt solubility, or reactivity issues. ${ }^{16-21}$ The development of novel salts has encountered problems related to salt solubility and corrosion of the aluminum current collector on the cathode..$^{21,22}$

One of the more interesting and promising alternative salts is lithium difluoro(oxalato) borate (LiDFOB). ${ }^{1,4,23,24}$ LiDFOB is promising due to good solubility, thermal stability, passivation of the aluminum current collector, stable SEI formation, and potentially lower cost. While there have been a limited number of investigations of LiDFOB as the conducting salt in the electrolyte, ${ }^{4,16,25}$ there have been several reports of the use of LiDFOB and the related salts lithium bis(oxalato) borate (LiBOB) and lithium tetrafluoro(oxalato) phosphate (LiTFOP) as additives to $\mathrm{LiPF}_{6}$ based electrolytes to form a more stable SEI. ${ }^{1,14,23,26-30}$ There have also been reports of the use of oxalate salts enabling the cycling of PC based electrolytes due to better SEI formation. ${ }^{30}$ The presence of the oxalate group in the anode thus may enable the use of EC free electrolytes and electrolytes with non-carbonate solvents.

The investigation of LiDFOB has been expanded to include carbonate free electrolyte formulations. Esters and lactones are an interesting alternative to carbonate solvents. Linear esters have been studied as co-solvents due to the high dielectric constants and low freezing points which have been reported to improve the low temperature performance of lithium ion batteries, ${ }^{15}$ while lactones such as $\gamma$-butyrolactone (GBL) have high dielectric constants ${ }^{5}$ and a very

\footnotetext{
*Electrochemical Society Student Member.

**Electrochemical Society Active Member.

${ }^{\text {z} E-m a i l: ~ b l u c h t @ c h m . u r i . e d u ~}$
}

wide liquid temperature range ( -43.5 to $204^{\circ} \mathrm{C}$ ). However, the use of GBL as a primary solvent in lithium ion battery electrolytes has been plagued by problems with the stability of the anode SEI. ${ }^{5}$ Despite the issues with GBL as a solvent in carbonate based electrolytes, GBL has been studied with LiBOB based electrolytes due to the limited solubility of LiBOB in carbonates. ${ }^{18,31}$ In order to investigate the use of novel electrolyte formulations for lithium ion batteries, a comparative study of three electrolytes has been conducted; a standard $\mathrm{LiPF}_{6}$ electrolyte in 1:1:1 EC/ dimethyl carbonate (DMC)/ diethyl carbonate (DEC) was tested against $1 \mathrm{M}$ LiDFOB in 1:1:1 EC/DMC/DEC and $1 \mathrm{M}$ LiDFOB in 1:1 GBL/MB (MB is methyl butyrate).

\section{Experimental}

LiDFOB was made following previously published procedures. ${ }^{4}$ The standard electrolyte $1 \mathrm{M} \mathrm{LiPF}_{6}$ in 1:1:1 EC/DMC/DEC, and battery grade solvents EC, DMC, and DEC were provided by BASF. GBL and MB were purchased from Sigma Aldrich in high purity and were dried with molecular sieves. The GBL was also distilled. $1 \mathrm{M}$ LiDFOB in EC/DMC/DEC (1:1:1 by volume) and $1 \mathrm{M}$ LiDFOB in GBL/MB (1:1 by volume, as a simple binary solvent system) were prepared in an argon filled glove box. 2032 coin cells were prepared with an anode composed of G5 graphite (89\% G5 Graphite, $2 \%$ Super $\mathrm{P}$ carbon, $8.9 \% \mathrm{PVdF}, 0.1 \%$ adhesive enhancer) and a cathode composed of $\mathrm{LiNi}_{0.80} \mathrm{Co}_{0.15} \mathrm{Al}_{0.05} \mathrm{O}_{2}$ (89\% LNMAO, 2\% KS15 graphite, $2 \% \mathrm{SAB}, 2 \%$ Super P carbon, $5 \% \mathrm{PVdF}$ ) and were provided by Yardney Technical Products. The separator was polyolefin (polyethylene) Setela E20MMS.

Conductivity measurements were acquired between $-20^{\circ} \mathrm{C}$ and $40^{\circ} \mathrm{C}$ with an Orion 3 Star conductivity meter from Thermo Scientific. 10 to $15 \mathrm{~mL}$ of electrolyte was added to a glass tube and sealed. The samples were allowed to equilibrate at each temperature for at least two and a half hours. The experiment was carried out in a Tenney JTR environmental chamber.

Viscosity measurements were taken using a glass capillary viscometer. Using the well-established density and viscosity of water at $20^{\circ} \mathrm{C}^{32}$ the viscosities of the standard $1 \mathrm{M} \mathrm{LiPF}_{6}$ in EC/DMC/DEC and the $1 \mathrm{M} \mathrm{LiDFOB}$ in GBL/MB were calculated using Equation 1:

$$
\eta_{2}=\frac{\eta_{1} \times \rho_{2} t_{2}}{\rho_{1} t_{1}}
$$

Where $\eta, \rho$, and $t$ are viscosity in $\mathrm{mPa} \mathrm{s}$, density in $\mathrm{g} \mathrm{mL}^{-1}$, and time in seconds. The average time and standard deviation were also calculated. The samples were maintained in an environmental chamber set at $20^{\circ} \mathrm{C}$ for at least four hours to ensure that the temperature was con- 
stant. Density was calculated for the samples in a $10 \mathrm{~mL}$ volumetric flask and with the sample at $20^{\circ} \mathrm{C}$.

To test the cycling performance of the electrolyte formulations, three replicate cells of each electrolyte formulation underwent formation cycling that consisted of one $\mathrm{C} / 20$ cycle, followed by two $\mathrm{C} / 10$ cycles, and concluded with two $\mathrm{C} / 5$ cycles at $16^{\circ} \mathrm{C}$. Each set of cells was then cycled for 50 additional cycles at a $\mathrm{C} / 5$ rate. The $\mathrm{C}$ rates were based on theoretical capacity. After cycling the cells at room temperature, cells were cycled at a rate of $\mathrm{C} / 5$ for five cycles with the charge at $25^{\circ} \mathrm{C}$ and discharged at $-10^{\circ} \mathrm{C}$, to investigate the low temperature discharge performance, and cells were cycled for $20 \mathrm{C} / 5$ cycles at $55^{\circ} \mathrm{C}$, to study accelerated aging.

Electrochemical impedance spectroscopy (EIS) was conducted on cells after 25 cycles at $16^{\circ} \mathrm{C}$. Cells were charged at a $\mathrm{C} / 5$ rate to $4.1 \mathrm{~V}$ followed by holding at constant voltage for 10 hours. For EIS measurements, the cells were held again at constant voltage of $4.1 \mathrm{~V}$ for a half hour, and EIS was taken from $300 \mathrm{kHz}$ to $20 \mathrm{mHz}$.

Cells were opened in an argon filled glove box and washed three times with anhydrous DMC to remove the electrolyte and then dried overnight at room temperature under vacuum for surface analysis. FTIR-ATR (Fourier Transform Infrared Spectroscopy - Attenuated Total Reflectance) was acquired with a Bruker TENSOR 27 spectrometer with a germanium crystal and ATR accessory, and was purged continuously with nitrogen. Samples were analyzed at two separate locations on the electrode from 800 to $4,000 \mathrm{~cm}^{-1}$ with 128 scans. The SEM (Scanning Electron Microscope) images were taken using a JEOL 5900 at high vacuum and are secondary electron images. The samples briefly exposed to air during transfer from the glove box to the SEM. The XPS (X-ray Photoelectron Spectroscopy) was conducted with a PHI 5500 system using $\mathrm{Al} \mathrm{K} \alpha$ radiation source $(\mathrm{h} v=1486 \mathrm{eV}$ ) under ultrahigh vacuum. The spectra were analyzed and fitted by Multipak 6.1 and XPS peak software (version 4.1). Line syntheses of elemental spectra were conducted using Gaussian-Lorentzian (80:20) curve fitting. The concentrations $\left(C_{x}\right)$ of each element were calculated based on Equation 2:

$$
C_{x}=\frac{\left(I_{x} / S_{x}\right)}{\sum\left(I_{i} / S_{i}\right)}
$$

where $I_{x}$ is the intensity of the relative element, and $S_{x}$ is the sensitivity number of the element, the values obtained from the Multipak software. ${ }^{29}$ The $\mathrm{C} 1 \mathrm{~s}$ graphite (C-C) peak at $284.3 \mathrm{eV}$ was used to confirm the binding energy scale and the $\mathrm{F} 1 \mathrm{~s}$ peak for $\mathrm{LiF}$ at $685.0 \mathrm{eV}$ was used as a secondary reference..$^{14,21,33}$

\section{Results and Discussion}

Conductivity. - The conductivities of the three electrolytes are depicted in Figure 1. The conductivity of the standard electrolyte, $1 \mathrm{M}$ $\mathrm{LiPF}_{6}$ in 1:1:1 EC/DMC/DEC, and the conductivity of the $1 \mathrm{M}$ LiDFOB in 1:1 GBL/MB electrolyte are similar at room temperature. The standard electrolyte is slightly better than the LiDFOB in GBL/MB electrolyte at elevated temperatures, while the LiDFOB in GBL/MB electrolyte has better conductivity at lower temperatures.

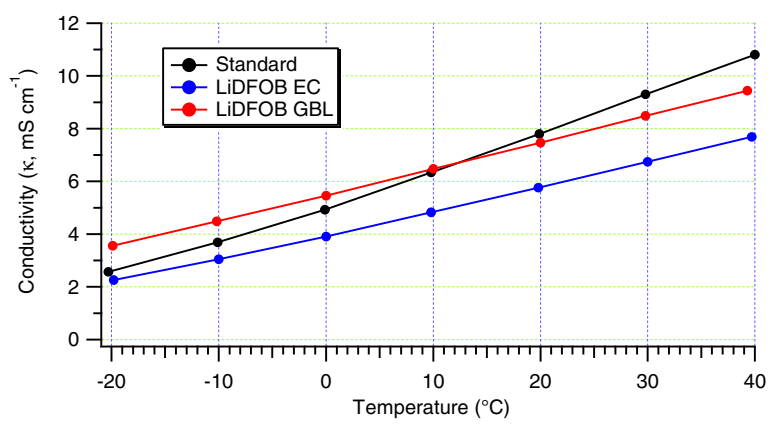

Figure 1. Conductivity measurements of the electrolyte systems used in the cells above.

\section{Table I. Viscosity of the standard electrolyte and the LiDFOB in GBL/MB electrolyte.}

\begin{tabular}{lcc} 
& STD & LiDFOB GBL \\
\hline Density $(\mathrm{g} / \mathrm{mL})$ & 1.21 & 1.09 \\
Viscosity $(\mathrm{mPa} \mathrm{s}, \mathrm{cP})$ & 3.57 & 2.94 \\
Error $(\%)$ & 0.1 & 0.6
\end{tabular}

This suggests that the LiDFOB in GBL/MB electrolyte may afford better performance at low temperature. In contrast, the $1 \mathrm{M} \mathrm{LiDFOB}$ in 1:1:1 EC/DMC/DEC electrolyte has lower conductivity than the standard electrolyte or the LiDFOB in GBL/MB electrolyte. Interestingly, the conductivity of the two LiDFOB electrolytes have a parallel relationship.

Viscosity.- The viscosity of the standard electrolyte is slightly higher than the viscosity of LiDFOB in GBL/MB electrolyte as provided in Table I, with the standard electrolyte having a viscosity of $3.57 \mathrm{mPa} s$ and the LiDFOB in GBL/MB electrolyte having a viscosity of $2.94 \mathrm{mPa}$ s. The lower viscosity of the LiDFOB in GBL/MB electrolyte can be attributed to the lower density of the electrolyte and the low viscosities of the solvents. The higher viscosity of the standard electrolyte is partially due to the higher density, but largely due to the high viscosity of EC.

Electrochemical cycling.- The cells containing $1 \mathrm{M}$ LiDFOB electrolytes cycle comparably to the cells containing standard electrolyte (Figure 2). The cells containing standard electrolyte have an initial capacity of $\sim 120 \mathrm{mAh} \mathrm{g}^{-1}$ after formation cycling, but the capacity slowly rises during the next 25 cycles to reach a maximum of $150 \mathrm{mAh} \mathrm{g}^{-1}$. This may be due to slow wetting of the electrode with the EC based electrolyte. The $1 \mathrm{M} \mathrm{LiDFOB}$ in EC/DMC/DEC electrolyte has similar capacity to the cell containing the standard electrolyte except that the maximum capacity is slightly lower, $140 \mathrm{mAh}$ $\mathrm{g}^{-1}$. The LiDFOB in GBL/MB electrolyte does not follow the same gradually increasing capacity profile of the EC based electrolytes. A constant capacity between 140 and $150 \mathrm{mAh} \mathrm{g}^{-1}$, is maintained from the end of formation cycling throughout the next 50 cycles with a slight fade in capacity. The first cycle efficiency of the cells with the standard electrolyte is $68 \%$, while the cells containing LiDFOB in $\mathrm{EC} / \mathrm{DMC} / \mathrm{DEC}$ and LiDFOB in GBL/MB have comparable first cycle efficiencies of 67 and $72 \%$, respectively. The efficiencies stabilize around $99 \%$ for cells containing all electrolytes investigated.

In order to understand the performance of the novel electrolytes at different temperature extremes as required for EV applications, low temperature $\left(-10^{\circ} \mathrm{C}\right)$ discharge performance and moderately elevated temperature $\left(55^{\circ} \mathrm{C}\right)$ accelerated aging cycling performance were investigated. Cells containing standard electrolyte have the best discharge capacity $(\sim 135 \mathrm{mAh} / \mathrm{g})$ during low temperature discharge $\left(-10^{\circ} \mathrm{C}\right)$, while cells containing the LiDFOB in GBL/MB electrolyte have slightly lower discharge capacity $(\sim 115 \mathrm{mAh} / \mathrm{g})$ and cells con-

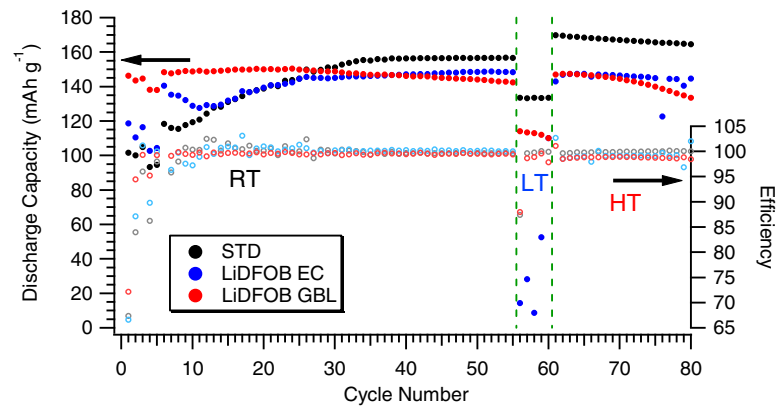

Figure 2. Cycling performance for various electrolyte formulations. The first 55 cycle are at room temperature $\left(\mathrm{RT}, 16^{\circ} \mathrm{C}\right)$, the next five are at low temperature $\left(\mathrm{LT},-10^{\circ} \mathrm{C}\right)$, and the last 20 are at high temperature $\left(\mathrm{HT}, 55^{\circ} \mathrm{C}\right)$. 


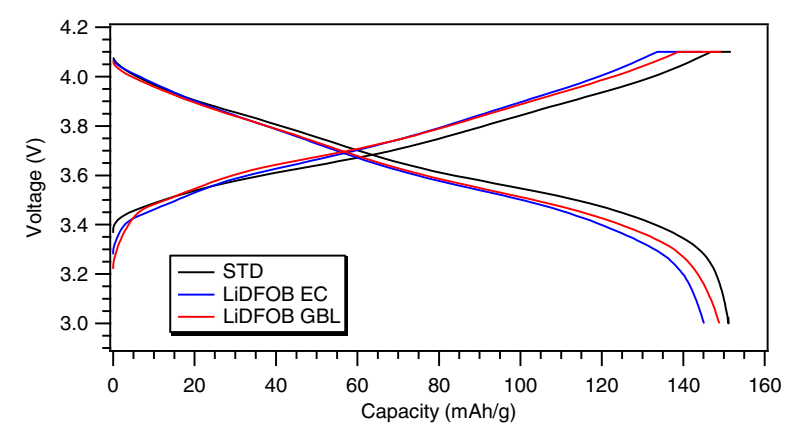

Figure 3. Charge/Discharge plot of the best cells at cycle 30 .

taining the LiDFOB in EC/DMC/DEC have the worst discharge performance $(\sim 20 \mathrm{mAh} / \mathrm{g})$. Upon cycling cells at $55^{\circ} \mathrm{C}$, a slight increase in capacity, compared to the RT cycling capacities, is observed initially followed by modest capacity fade. The cells with the best cycling performance at $55^{\circ} \mathrm{C}$ contain standard electrolyte with capacities of over $160 \mathrm{mAh} \mathrm{g}^{-1}$ and minimal fade. The LiDFOB in EC/DMC/DEC electrolyte also cycles well at $55^{\circ} \mathrm{C}$ reaching just above $140 \mathrm{mAh} \mathrm{g}^{-1}$ with little fade upon cycling. The LiDFOB in GBL/MB electrolyte has a minor increase in capacity upon cycling at $55^{\circ} \mathrm{C}$ with slightly greater capacity fade than is observed for the carbonate based electrolytes. However, the cycling performance of the LiDFOB in GBL/MB electrolyte is generally similar to the standard electrolyte and the slightly greater capacity fade upon cycling at $55^{\circ} \mathrm{C}$ may be due to the lower purity of the LiDFOB and ester and lactone solvents compared to the very high purity of the battery grade $\mathrm{LiPF}_{6}$ and carbonate solvents.

While there are performance differences in the various electrolyte formulations, they all have stable charge and discharge profiles as depicted for the $30^{\text {th }}$ cycle in Figure 3. The standard electrolyte has slightly more capacity, but the LiDFOB formulations are similar.

Electrochemical impedance spectroscopy.- The cells containing the different electrolytes are analyzed by electrochemical impedance spectroscopy (EIS) after the first 25 cycles at $16^{\circ} \mathrm{C}$ as depicted in Figure 4, along with an equivalent circuit. ${ }^{34}$ For the equivalent circuit, $R_{B}$ represents the bulk resistance of the cell, $R_{S L}$ represents the resistance of the surface layer including the SEI while $\mathrm{C}_{\mathrm{SL}}$ represents the

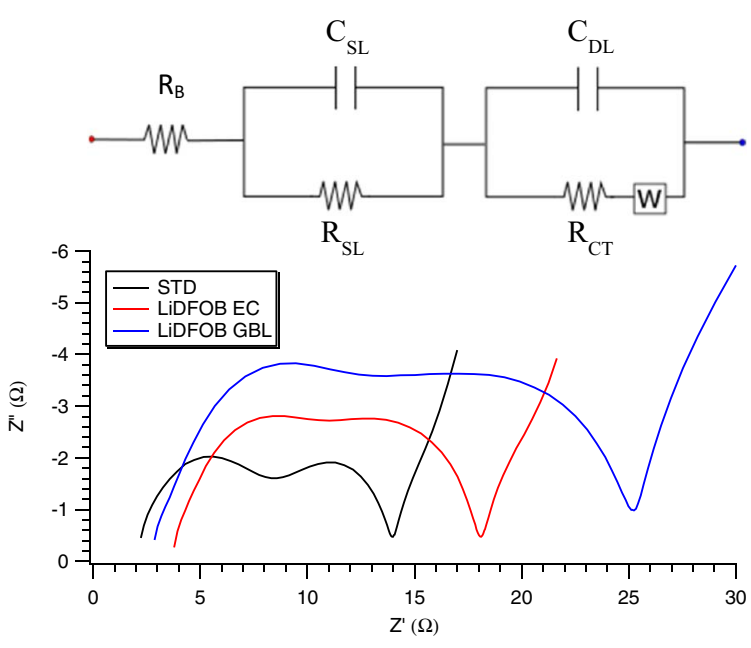

Figure 4. Electrochemical impedance spectroscopy after 25 cycles, including formation. $\mathrm{EC}$ denotes $\mathrm{LiDFOB} / \mathrm{EC} / \mathrm{DMC} / \mathrm{DEC}$ electrolyte formulation and GBL denotes LiDFOB/GBL/MB formulation.

capacitance of the surface layer and is the response to high AC frequencies, $\mathrm{R}_{\mathrm{CT}}$ represents the faradaic charge transfer resistance with $\mathrm{C}_{\mathrm{DL}}$ representing a double layer capacitance and are at mid-range frequencies, while $\mathrm{W}$ is representative of the Warburg impedance at low frequencies. ${ }^{34}$ As related to the EIS plots, the first semicircle at lower resistance can be attributed to the high frequencies, the second semicircle can be attributed to medium range frequencies, and the Warburg impedance is the strait line at a near $45^{\circ}$ angle and is at low frequencies. The impedance is smallest for the cell cycled with the standard electrolyte followed by the cell containing the LiDFOB in EC/DEC/DMC electrolyte while the cell containing the LiDFOB in GBL/MB electrolyte has the highest impedance. The changes in impedance are primarily related to changes in the surface layer and charge transfer resistances and may result from changes in the structure of the SEI as discussed below.

Scanning electron microscopy.- SEM images were acquired for both the anodes and cathodes extracted from cycled cells. Significant a

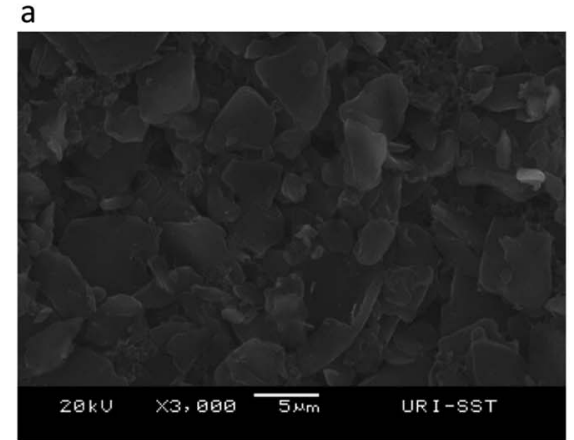

C

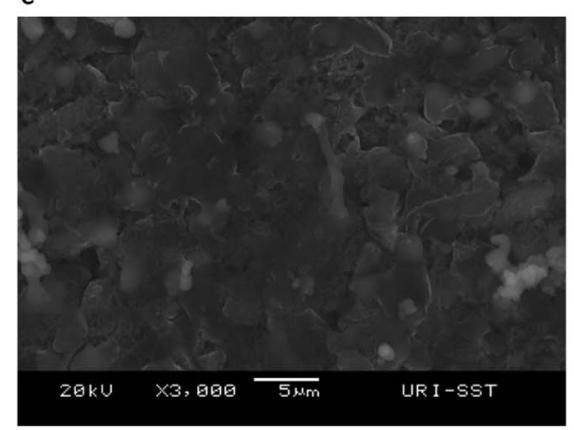

b

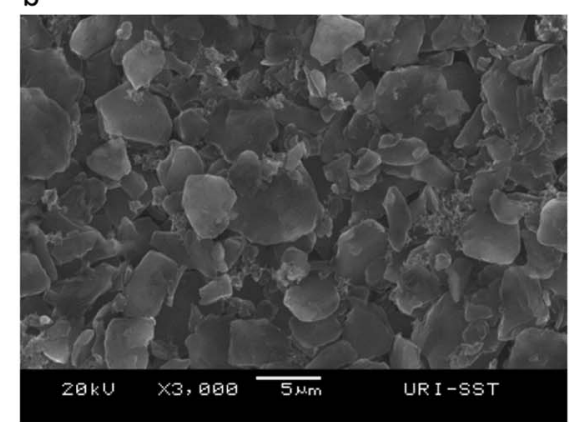

d

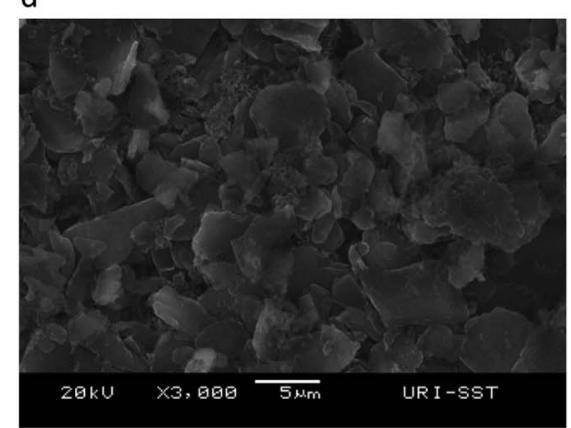

Figure 5. SEM images for anode of $[a]$ : Fresh [b]: Standard [c]: LiDFOB in EC/DMC/DEC and [d]: LiDFOB in GBL/MB. These samples were taken from the best performing samples and are secondary electron images. 
a

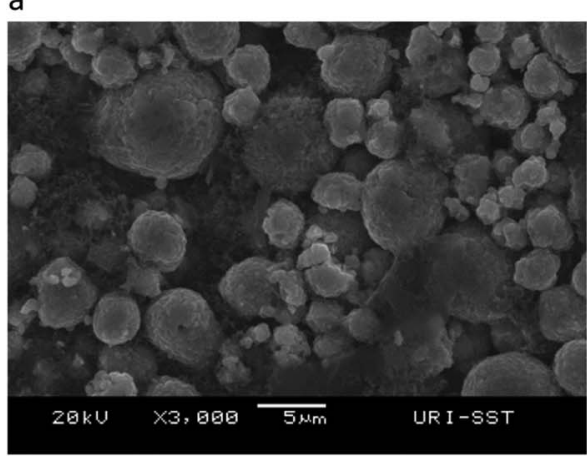

C

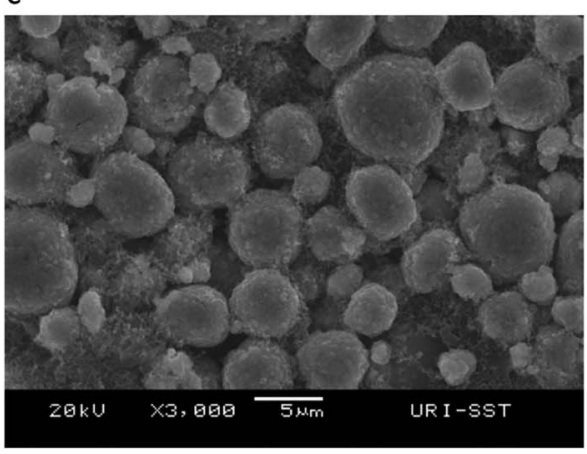

b

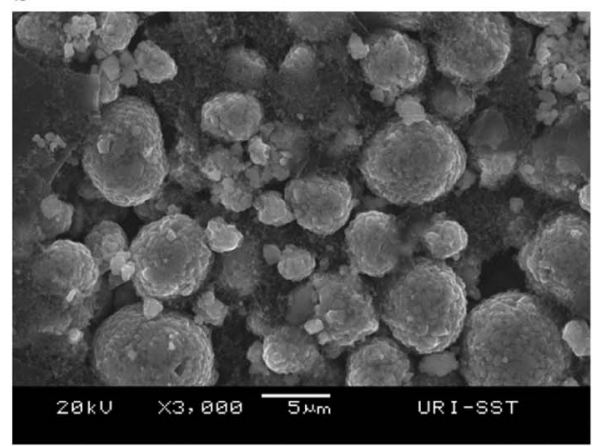

d

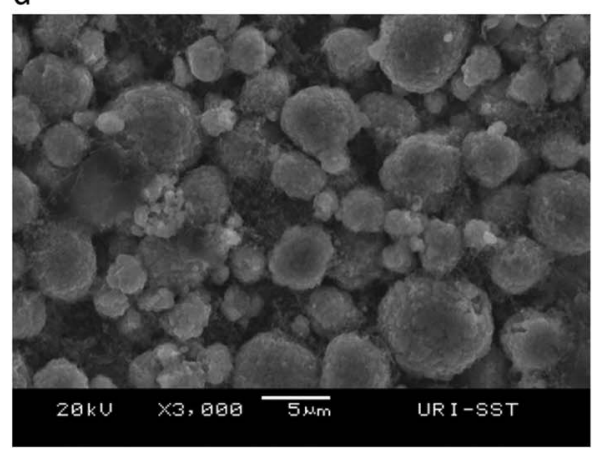

Figure 6. SEM images for cathode of [a]: Fresh [b]: Standard [c]: LiDFOB in EC/DMC/DEC and [d]: LiDFOB in GBL/MB. These samples were taken from the best performing samples and are secondary electron images. differences are observed for the anode surfaces cycled with the standard electrolytes compared to the LiDFOB electrolytes (Figure 5). The fresh anode particles have clean edges, and the graphite particles are well defined. After cycling in standard electrolyte, the graphite edges become slightly less defined, and the surface is covered with a thin film. The anode cycled with LiDFOB in EC/DMC/DEC electrolyte has a much thicker surface film which thoroughly covers the graphite. The anode cycled with the LiDFOB in GBL/MB electrolyte also has a very thick surface film although it is thinner than that observed with the LiDFOB in EC/DMC/DEC electrolyte.
The SEM Images of the cathodes are depicted in Figure 6 revealing less changes in morphology than observed for the anodes. The cathode cycled with the standard electrolyte is very similar to the fresh cathode suggesting little reaction of the electrolyte with the cathode surface. However the cathodes cycled with either of the LiDFOB electrolytes have a thin film on the surface of the cathode particles consistent with the reaction of the electrolyte on the cathode surface.

$X$-ray photoelectron spectroscopy.- The surface of both the anodes and the cathodes, fresh and after 55 cycles at $16^{\circ} \mathrm{C}$, were in-

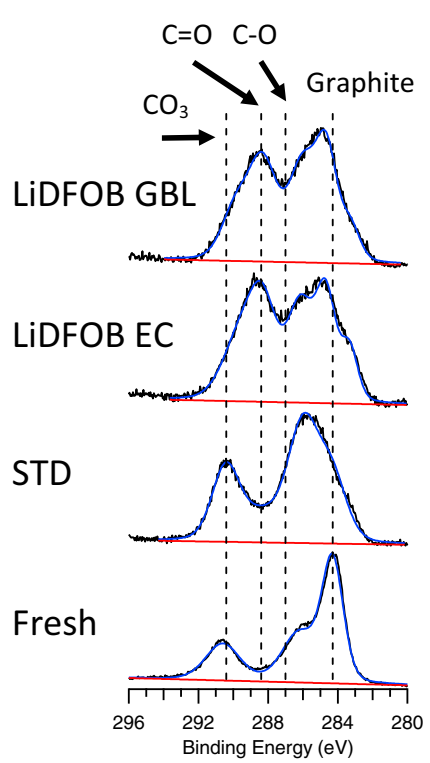

C1s

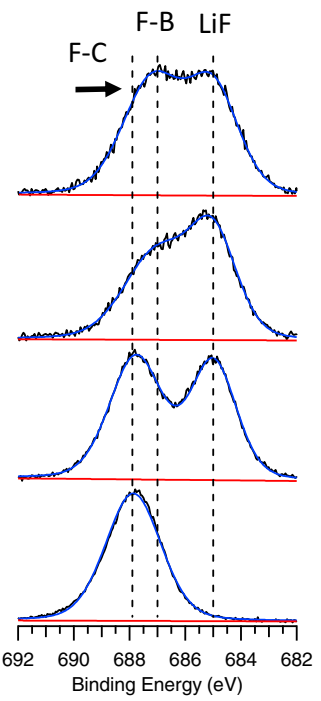

F1s
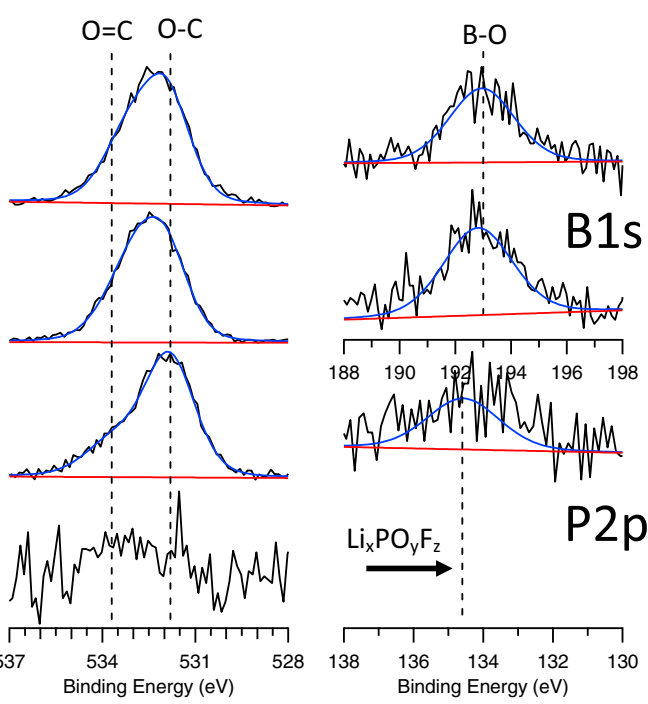

O1s

Figure 7. XPS spectra of the anode extracted from cells cycled with the three different electrolyte formulations. From left to right, the spectra are $\mathrm{C}$ 1s, $\mathrm{F} 1 \mathrm{~s}$, $\mathrm{O}$ $1 \mathrm{~s}$, and B 1s/P2p. From bottom to top is fresh anode, standard electrolyte, LiDFOB in EC/DMC/DEC, and LiDFOB in GBL/MB. 


\begin{tabular}{|c|c|c|c|c|c|}
\hline Sample & {$[\mathrm{B}] \%$} & {$[\mathrm{C}] \%$} & {$[\mathrm{~F}] \%$} & {$[\mathrm{O}] \%$} & {$[\mathrm{P}] \%$} \\
\hline Fresh & 0.0 & 68.5 & 30.6 & 0.8 & 0.0 \\
\hline Standard & 0.0 & 44.8 & 42.1 & 12.6 & 0.5 \\
\hline$L i D F O B-E C$ & 4.5 & 48.5 & 23.1 & 23.9 & 0.0 \\
\hline$L i D F O B-G B L$ & 3.7 & 49.1 & 24.0 & 23.2 & 0.0 \\
\hline
\end{tabular}

vestigated by XPS. The C 1s, F 1s, O 1s, B1s, and P2p element spectra of the anodes are provided in Figure 7 while the elemental integrations of the XPS spectra are provided in Table II. The fresh anode is dominated by carbon and fluorine from the graphite and the PVDF binder with low concentrations of oxygen due to the presence of oxygenated impurities on the surface of the graphite. Upon cycling with the standard electrolyte the concentration of $\mathrm{F}, \mathrm{O}$ and $\mathrm{P}$ are increased while the concentration of $\mathrm{C}$ is decreased consistent with electrolyte decomposition on the anode surface. With both LiDFOB electrolytes the decrease in $\mathrm{C}$ concentration is similar to the standard electrolyte however the $\mathrm{F}$ concentration is also decreased and the $\mathrm{O}$ and $\mathrm{B}$ concentrations are increased. Again the changes are consistent with electrolyte decomposition on the anode surface. Interestingly, the elemental concentrations of the anode cycled with the LiDFOB in $\mathrm{EC} / \mathrm{DMC} / \mathrm{DEC}$ and the LiDFOB in GBL/MB are very similar.

The fresh anode contains $\mathrm{C} 1 \mathrm{~s}$ peaks at $284.3 \mathrm{eV}$ characteristic of graphite and 286.2 and $290.6 \mathrm{eV}$ for the PVDF binder. The corresponding F1s peak of PVDF is observed at $687.9 \mathrm{eV}$. The XPS spectra of the graphite anodes cycled with the standard electrolyte are similar to those previously reported. ${ }^{19}$ The $\mathrm{C} 1 \mathrm{~s}$ spectrum contains new peaks at 287 and $290 \mathrm{eV}$ characteristic of $\mathrm{C}-\mathrm{O}$ and $\mathrm{CO}_{3}{ }^{-}$containing species. The $\mathrm{O} 1 \mathrm{~s}$ spectrum contains peaks at 531.8 and $533.7 \mathrm{eV}$ characteristic of $\mathrm{C}-\mathrm{O}$ and $\mathrm{CO}_{3}{ }^{-}$containing species. The $\mathrm{C} 1 \mathrm{~s}$ and $\mathrm{O} 1 \mathrm{~s}$ data is consistent with the presence of lithium alkyl carbonates and $\mathrm{Li}_{2} \mathrm{CO}_{3}$. The F1s spectrum contains a new peak at $685.0 \mathrm{eV}$ characteristic of $\mathrm{LiF}$ and a small new weak peak at $134.6 \mathrm{eV}$ in the P2p spectrum characteristic of $\mathrm{Li}_{\mathrm{x}} \mathrm{PO}_{\mathrm{y}} \mathrm{F}_{\mathrm{z}}$. However, the SEI is relatively thin since the peaks associated with PVDF are still observed in the C1s and F1s

\begin{tabular}{|c|c|c|c|c|c|}
\hline Sample & {$[\mathrm{B}] \%$} & {$[\mathrm{C}] \%$} & {$[\mathrm{~F}] \%$} & {$[\mathrm{O}] \%$} & {$[\mathrm{Ni}] \%$} \\
\hline Fresh & 0.0 & 70.8 & 16.2 & 9.9 & 3.0 \\
\hline Standard & 0.0 & 63.4 & 24.7 & 9.4 & 2.5 \\
\hline LiDFOB-EC & 4.8 & 56.7 & 10.5 & 26.6 & 1.4 \\
\hline$L i D F O B-G B L$ & 5.1 & 55.1 & 9.0 & 29.9 & 1.0 \\
\hline
\end{tabular}

spectra. The XPS spectra of the surface of the anodes cycled with LiDFOB electrolytes are significantly different than the XPS spectra observed for the standard electrolyte. This is expected since it has been reported that LiDFOB is involved in SEI formation. ${ }^{1,4,23,25,26,28}$ However, the XPS spectra of the surface of the anode cycled with the LiDFOB in EC/DMC/DEC and the anode cycled with LiDFOB in GBL/MB are very similar. This suggests that reduction of LiDFOB is the dominant SEI forming reaction in both LiDFOB electrolytes. The $\mathrm{C} 1 \mathrm{~s}$ spectrum is dominated by a peak at $288.3 \mathrm{eV}$ characteristic of $\mathrm{C}=\mathrm{O}$ containing species such as lithium oxalate or other oxalate containing species. The corresponding oxalate peak is observed in the $\mathrm{O} 1 \mathrm{~s}$ spectrum at $531.9 \mathrm{eV}$. A strong peak associated with $\mathrm{LiF}$ is observed at $685.0 \mathrm{eV}{ }^{14,33}$ In addition, there is a new peak in the B1s spectrum at $193 \mathrm{eV}$ characteristic of B-O containing species. ${ }^{14,33}$ The B-O peaks occur at $533 \mathrm{eV}$ and overlap with $\mathrm{C}-\mathrm{O}$ peaks. The surface films for both LiDFOB electrolytes are thick since the peaks associated with the PVDF binder (291 eV C1s, and $688 \mathrm{eV} \mathrm{F1s)} \mathrm{are} \mathrm{weak.}$

The XPS spectra of the cathodes cycled with different electrolytes are provided in Figure 8 while the elemental concentrations of the fresh and cycled cathodes are summarized in Table III. The fresh cathode has a high concentration of $\mathrm{C}$ and $\mathrm{F}$ from the conductive carbon and PVDF binder and low concentrations of $\mathrm{O}$ and $\mathrm{Ni}$ from the metal oxide. Upon cycling with the standard electrolyte only small changes are observed in the elemental concentrations consistent with small changes to the surface of the cathode. Much larger changes are observed with both LiDFOB electrolytes. The concentrations of $\mathrm{C}, \mathrm{F}$, and $\mathrm{Ni}$ are decreased while the concentrations of $\mathrm{O}$ and $\mathrm{B}$ are increased consistent with the formation of a cathode surface film com-

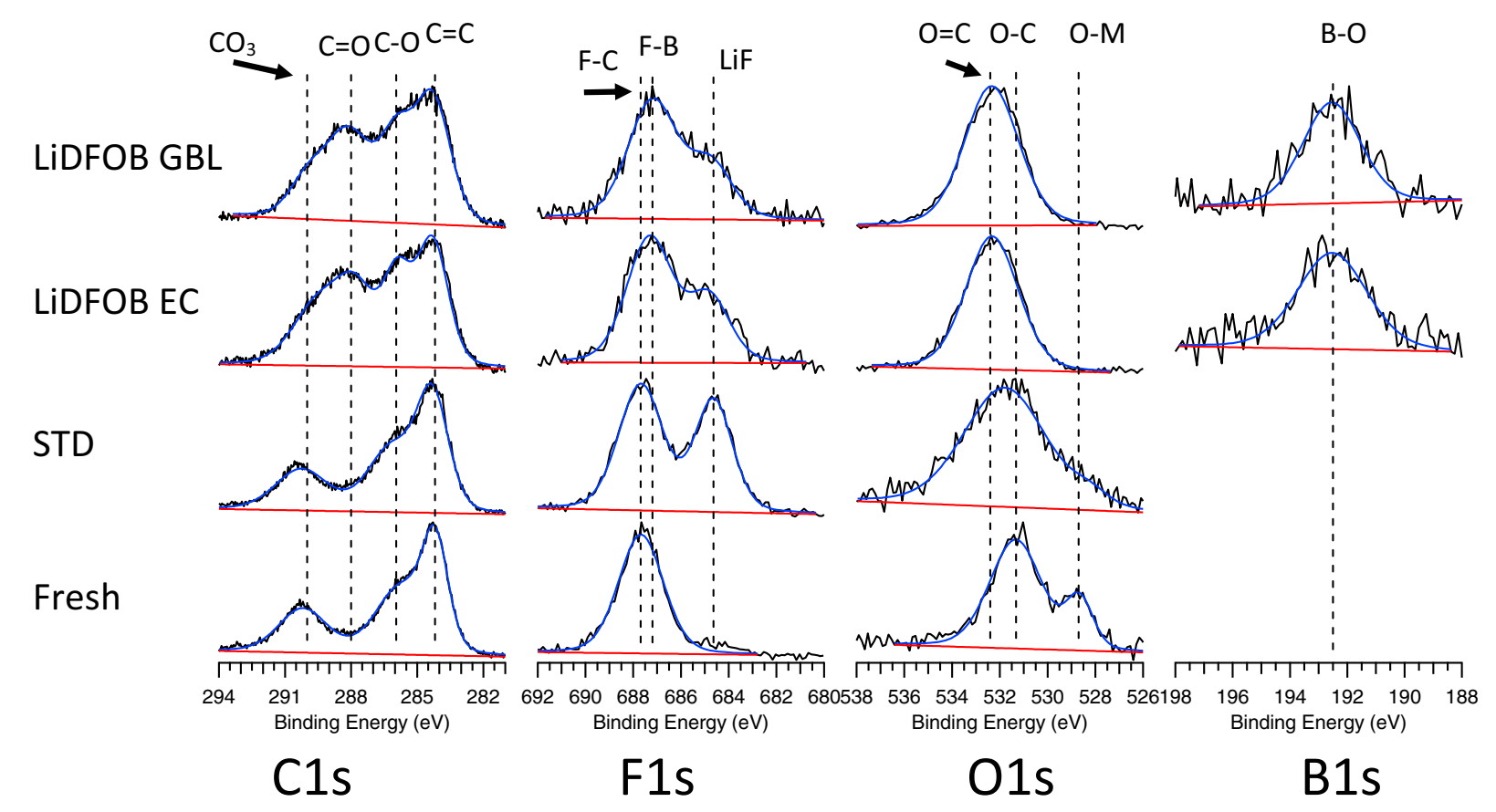

Figure 8. XPS spectra of the cathodes cycled with the different electrolyte formulations. From left to right, the spectra are C 1s, F 1s, O 1s, and B 1s. From bottom to top is fresh cathode, standard electrolyte, LiDFOB in EC/DMC/DEC, and LiDFOB in GBL/MB. 


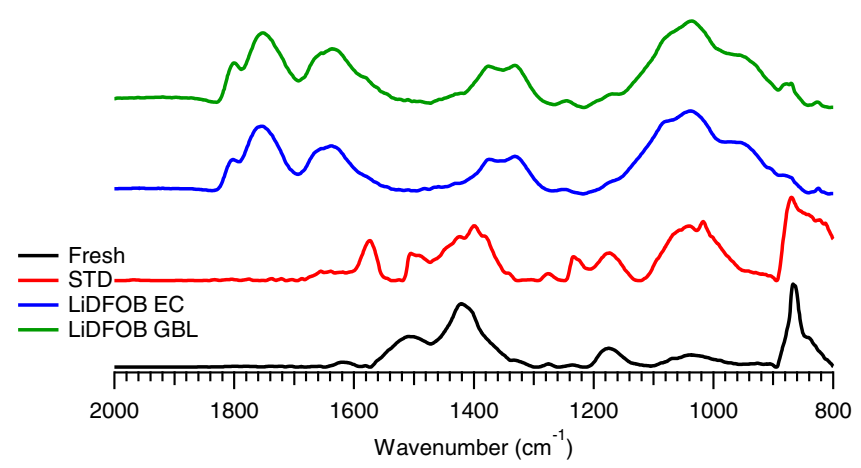

Figure 9. FTIR-ATR spectra of anodes.

posed of electrolyte decomposition products. The elemental surface concentrations of the two LiDFOB electrolytes are very similar suggesting similar surface film structure.

The fresh cathode has $\mathrm{C} 1 \mathrm{~s}$ peaks at $284.2 \mathrm{eV}$ for the conductive carbon and at 285.7 and $290.2 \mathrm{eV}$ for the PVDF binder. The related F1s peak for PVDF is observed at $687.7 \mathrm{eV}$. The $\mathrm{O} 1 \mathrm{~s}$ spectrum contains peaks at 531.3 and $528.7 \mathrm{eV}$ characteristic of residual $\mathrm{Li}_{2} \mathrm{CO}_{3}$ on the surface and the metal oxide, respectively. The corresponding metal oxide peak is also observed in the Ni2p spectrum at $855.6 \mathrm{eV}$ in the Ni2p spectrum. After cycling in the presence of the standard electrolyte only small changes are observed to the surface of the cathode. A new peak is observed in the F1s spectrum at $684.6 \mathrm{eV}$ characteristic of $\mathrm{LiF}$ and the peak associated with the metal oxide $(528 \mathrm{eV})$ in the $\mathrm{O} 1 \mathrm{~s}$ spectrum is slightly diminished consistent with the generation of a thin surface film. The surfaces of the cathodes cycled with both LiDFOB electrolytes have significant changes upon cycling. The $\mathrm{C} 1 \mathrm{~s}$ spectra contain a new peak at $288 \mathrm{eV}$ characteristic of lithium oxalate or other oxalates and the corresponding $\mathrm{O} 1 \mathrm{~s}$ peak is observed at $532.4 \mathrm{eV}$ in the $\mathrm{O} 1 \mathrm{~s}$ spectrum. In addition, peaks are observed in the B1s spectra at $192.5 \mathrm{eV}$ consistent with the presence of borates, as previously reported on the surface of cathodes cycled with LiDFOB or LiBOB. ${ }^{14,28}$ The cathode surface film is thinner than the SEI observed on the anodes cycled with the LiDFOB electrolytes, since the peaks associated with the PVDF binder are still observable at 290.5 and $286 \mathrm{eV}$, but thicker than the surface film observed on the cathode cycled with the standard electrolyte since the peak associated with the metal oxide is no longer observable.

Infra-Red spectroscopy.- The anodes and cathodes extracted for cells cycled with different electrolytes were investigated by IR-ATR spectroscopy (Figure 9 and Figure 10). The fresh anode contains absorptions characteristic of PVDF at 870,1410 , and $1500 \mathrm{~cm}^{-1} .14,30,35$ The spectrum for the anode cycled with the standard electrolyte is very similar to that of the fresh anode, except there is a new weak absorption at $1600 \mathrm{~cm}^{-1}$ consistent with the presence of lithium alkyl carbonates

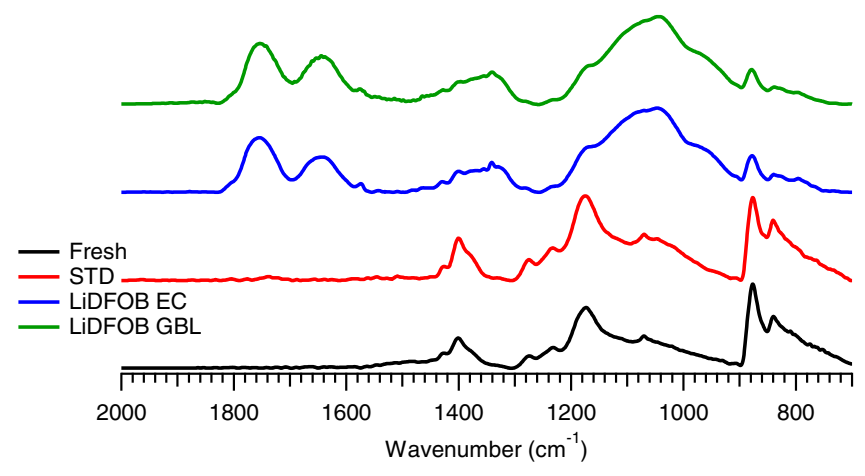

Figure 10. FTIR-ATR of cathode samples. and a strong absorption at $1420 \mathrm{~cm}^{-1}$ characteristic of $\mathrm{Li}_{2} \mathrm{CO}_{3}$. The IR spectra of the anodes cycled with the LiDFOB electrolytes are very similar to each other, and different from the IR spectra of the anode cycled with the standard electrolyte. New peaks are observed at 1630 and $1760 \mathrm{~cm}^{-1}$ characteristic of lithium oxalates and oligocarbonates, respectively. ${ }^{29}$

The IR spectrum of the fresh cathode is dominated by the peaks associated with the PVDF binder. The IR spectrum of the cathode cycled with the standard electrolyte is also dominated by the PVDF binder. The IR spectra of the cathodes cycled with the LiDFOB electrolytes have new absorptions at 1630 and $1760 \mathrm{~cm}^{-1}$ consistent with the presence of lithium oxalates and oligocarbonates, respectively. ${ }^{29}$

\section{Conclusions}

A novel electrolyte formulation without any $\mathrm{LiPF}_{6}$ or carbonate solvents has been developed and investigated in lithium ion batteries. The $1 \mathrm{M}$ LiDFOB in GBL/MB electrolyte has comparable ionic conductivity and room temperature cycling performance to the industry standard electrolyte, $1 \mathrm{M} \mathrm{LiPF}_{6}$ in 1:1:1 EC/DMC/DEC. Cells containing the LiDFOB in GBL/MB electrolyte also have a slightly decreased discharge performance at $-10^{\circ} \mathrm{C}$ and have good capacity retention upon cycling at $55^{\circ} \mathrm{C}$, to simulate accelerated aging. Cells containing the LiDFOB in GBL/MB electrolyte have slightly higher impedance than cells cycled with the standard electrolyte. The slightly decreased capacity at low temperature is in contrast to the superior conductivity at low temperature and is likely due to the increased cell impedance due to changes in the structure of the SEI. Thus upon developing new electrolytes it is important to analyze both the bulk properties of the electrolyte and the interfacial reactions of the electrolyte with the electrode materials.

Ex-situ surface analysis provides insight into the role of the LiDFOB salt in SEI formation and cell cycling performance. XPS and IR spectroscopy confirm that the structure of the anode SEI is dominated by the decomposition products of LiDFOB. The anode SEI generated for both the LiDFOB in GBL/MB electrolyte and the LiDFOB in $\mathrm{EC} / \mathrm{DMC} / \mathrm{DEC}$ electrolyte have nearly identical structure. The anode SEI is dominated by the presence of lithium oxalate, other oxalate containing species, and borates and is much thicker than the anode SEI generated with the standard electrolyte. The surface films on the cathodes cycled with the LiDFOB electrolytes have similar structure to the anode SEI and are thicker than the surface films generated on the cathode cycled with the standard electrolyte. The thick surface films composed of the decomposition products of LiDFOB passivate the surface of the anode and enable stable cycling performance in the presence of the all ester electrolyte. Depending upon the electrolyte the reduction products of either the salt or the solvent can dominate the structure of the SEI.

\section{Acknowledgments}

We thank Optodot and the US Department of Energy grant number DE-EE0005433 for funding, BASF for providing electrolyte, and Yardney Technical products for providing electrodes and separators.

\section{References}

1. V. Aravindan, J. Gnanaraj, S. Madhavi, and H.-K. Liu, Chem. Eur. J., 17, 14326 (2011).

2. J. B. Goodenough and K.-S. Park, J. Am. Chem. Soc., 135, 1167 (2013).

3. V. Etacheri, R. Marom, R. Elazari, G. Salitra, and D. Aurbach, Energy Environ. Sci., 4, 3243 (2011).

4. S. S. Zhang, Electrochem. Commun., 8, 1423 (2006).

5. K. Xu, Chem. Rev., 104, 4303 (2004).

6. C. L. Campion, W. Li, and B. L. Lucht, J. Electrochem. Soc., 152, A2327 (2005).

7. W. Li, C. Campion, B. L. Lucht, B. Ravdel, and K. M. Abraham, J. Electrochem. Soc., 152, A1361 (2005).

8. S. E. Sloop, J. B. Kerr, and K. Kinoshita, J. Power Sources, 119-121, 330 (2003).

9. K. Xu, Y. Lam, S. S. Zhang, T. R. Jow, and T. B. Curtis, J. Phys. Chem. C, 111, 7411 (2007).

10. M. Nie, D. Chalasani, D. P. Abraham, Y. Chen, A. Bose, and B. L. Lucht, J. Phys Chem. C, 117, 1257 (2013)

11. P. Verma, P. Maire, and P. Novák, Electrochim. Acta, 55, 6332 (2010). 
12. P. Lu, C. Li, E. W. Schneider, and S. J. Harris, J. Phys. Chem. C, 118, 896 (2014).

13. K. Xu, Energies, 3, 135 (2010).

14. M. Nie and B. L. Lucht, J. Electrochem. Soc., 161, A1001 (2014).

15. M. C. Smart, B. V. Ratnakumar, K. B. Chin, and L. D. Whitcanack, J. Electrochem. Soc., 12, A1361 (2010).

16. S. Li, W. Zhao, X. Cui, Y. Zhao, B. Li, H. Zhang, Y. Li, G. Li, X. Ye, and Y. Luo, Electrochim. Acta, 91, 282 (2013).

17. K. Xu, S. S. Zhang, and T. R. Jow, J. Electrochem. Solid-State Lett., 5, A26 (2002).

18. K. Xu, J. Electrochem. Soc., 155, A733 (2008).

19. Z. Zhang, L. Hu, H. Wu, W. Weng, M. Koh, P. C. Redfern, L. A. Curtiss, and K. Amine, Energy Environ. Sci., 61806 (2013).

20. W. Xu, A. J. Shusterman, M. Videa, V. Velikov, R. Marzke, and C. A. Angell, J. Electrochem. Soc., 150, E74 (2003).

21. Y. Yamada, K. Usui, C. H. Chiang, K. Kikuchi, K. Furukawa, and A. Yamada, Appl. Mater. Interfaces, 6, 10892 (2014).

22. D. W. McOwen, D. M. Seo, O. Borodin, J. Vatamanu, P. D. Boyle, and W. A. Henderson, Energy Environ. Sci., 7, 416 (2014).
23. S. S. Zhang, J. Power Sources, 163, 713 (2007).

24. S. Zugmann, M. Fleischmann, M. Amereller, R. M. Gschwind, M. Winter, and H. J. Gores, J. Chem. Eng. Data, 56, 4786 (2011).

25. M. H. Fu, K. L. Haung, S. Q. Liu, J. S. Liu, and Y. K. Li, J. Power Sources, 195, 862 (2010).

26. I. A. Shkrob, Y. Zhu, T. W. Marin, and D. P. Abraham, J. Phys. Chem. C, 117, 23750 (2013).

27. H. Zhou, Z. Fang, and J. Li, J. Power Sources, 230, 148 (2013).

28. M. Xu, L. Zhou, L. Hao, L. Xing, W. Li, and B. L. Lucht, J. Power Sources, 196, 6794 (2011).

29. M. Xu, A. Xiao, W. Li, and B. L. Lucht, J. Electrochem. Soc., 157, A115 (2010).

30. L. Zhou and B. L. Lucht, J. Power Sources, 205, 439 (2012).

31. D. Belov and D. T. Shieh, J. Solid State Electrochem., 16, 603 (2012).

32. J. Kestin, M. Sokolov, and W. A. Wakeham, J. Phys. Chem. Ref. Data, 7, 941 (1978).

33. E. A. Il'inchik, V. V. Volkov, and L. N. Mazalov, J. Struct. Chem., 46, 523 (2005).

34. S. S. Zhang, K. Xu, and T. R. Jow, J. Power Sources, 115, 137 (2003).

35. T. Boccaccio, A. Bottino, G. Capannelli, and P. Piaggo, J. Membr. Sci., 210, 315 (2002). 